\title{
Footing is Not Always about Stress: Formalizing Variable High Vowel Deletion in Québec French
}

\author{
Guilherme D. Garcia, Heather Goad, and Natália Brambatti Guzzo \\ McGill University
}

\section{Introduction}

Research in prosodic phonology has shown that phonological phenomena apply with reference to a limited number of hierarchically organized units that are larger than the segment (Selkirk 1984; Nespor and Vogel 1986; McCarthy and Prince 1995). Two of the prosodic domains, namely the foot and the phonological word, are identified and motivated based on the manifestation of lexical stress: the foot is the domain where stress is realized, while the phonological word is the domain where stress is computed (see prosodic hierarchy in Figure 1).

Figure 1: Partial hierarchy of prosodic domains.

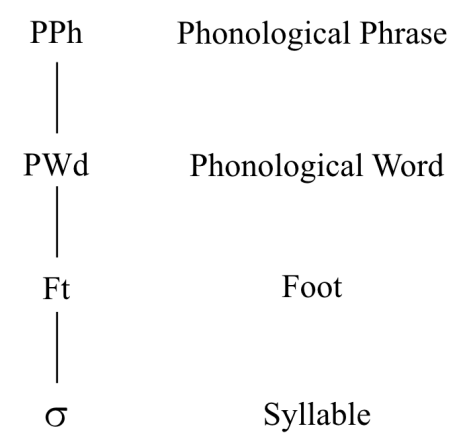

The prosodic domains in Figure 1 are typically assumed to be universal (Selkirk 1984, 1996; Nespor and Vogel 1986; Vogel 2010). However, for languages that lack lexical stress, such as French, the existence of the foot and phonological word has been questioned. In different varieties of French, including Québec French, the variety on which we focus, the only obligatory position for prominence is the right edge of the phonological phrase, regardless of how many phonological words it contains (Dell 1984; Jun and Fougeron 2000 for European French; Thibault and Ouellet 1996 for Québec French); see (1). This observation has led some researchers to analyze French 'stress' as intonational prominence, and French as a foot-less language (e.g., Jun and Fougeron 2000).

(1) [lə movez avo'ka $]_{\mathrm{PPh}}$

le mauvais avocat

'the bad avocado'

Although foot structure in Québec French cannot be identified based on the manifestation of prominence, in this paper we argue that a different phonological process, namely, high vowel deletion (HVD), motivates

\footnotetext{
* Contact: guilherme.garcia@mail.mcgill.ca, heather.goad@mcgill.ca, nataliaguzzo@me.com. Authors'names are in alphabetical order. This work was supported by grants from FRQSC and SSHRC. We would like to thank Amélie Bernard, Jeff Lamontagne, Yvan Rose, Morgan Sonderegger, and Francisco Torreira for their input on various aspects of this work.
} 
the existence of iterative iambic footing in the language. HVD never targets vowels in final prominent position, which is an indication that the process is sensitive to rhythmic structure in some way. However, there is disagreement about whether high vowels in some or all positions upstream of the final vowel can be equally targeted. While Cedergren (1986) argues that any non-final high vowel can be deleted (e.g., [alØmãtasjõ] alimentation 'nourishment', [organØzatœr] organisateur 'organizer'), Verluyten (1982) proposes that deletion preferably targets high vowels in even-numbered syllables from the right word edge ([alØmãtasjõ $]>$ [organØzatœr]).

HVD applies variably, which we reason underlies the disagreement regarding whether or not the process is sensitive to rhythmic structure. We show that when the conditions on variation are experimentally controlled for, evidence for iterative iambic footing emerges, consistent with Verluyten's (1982) hypothesis. We also show that there are competing factors regulating the application of HVD. We formalize these observations in a MaxEnt Grammar (Goldwater and Johnson 2003; Hayes and Wilson 2008), which (i) allows candidates to be probabilistically assessed, thus capturing the variation, and (ii) allows for gang-up effects, where two or more lower-ranked constraints can overrule the effects of a higher-ranked constraint, thus capturing the competing factors. In the next section, we turn to other evidence, aside from prominence, for and against the existence of foot structure in (Québec) French.

\section{Is French a foot-less language?}

As mentioned earlier, the observation that (Québec) French only requires prominence to be realized at the right edge of the phonological phrase has led researchers to propose that the language has no foot structure (Jun and Fougeron 2000); see (1) in the previous section. Additional evidence is consistent with this view. For example, French allows rampant violations of word minimality, since monosyllabic lexical words with short vowels and no codas are frequently attested (e.g., Scullen 1997); see (2).
(2) a. $[1 \varepsilon]$
b. $\left[\int \mathrm{a}\right]$
lait
chat
'milk'
'cat'

Furthermore, French exhibits unusual patterns of (optional) secondary 'stress' (e.g., Fónagy 1979; Déchaine 1990; Scullen 1997; Goad and Prévost 2011). Secondary stress does not apply in alternating fashion, but typically falls at the left edge of the leftmost phonological word within a phrase. It is thus not rhythmic, unlike what is observed in English or other Romance languages. This is particularly evident in phrases that contain more than one lexical word: a maximum of two positions of prominence is permitted; see (3).

(3) a. [,kõpresibili'te], *[k̃̃,presi, bili'te]

compressibilité

'compressibility'

b. [, kərdəlદt o' rãz] [kordə, lkt o' rãz], *[, kordə, let o' rãz]

cordelette orange

'orange rope.DIM'

While the free violations of word minimality and the patterns of secondary prominence are consistent with French being foot-less, evidence from other phonological phenomena suggests the opposite. For example, truncation of polysyllabic words typically results in disyllabic forms with final prominence (4) (e.g., Scullen 1997). In other words, the shape of truncated forms corresponds to an iambic foot.

(4) a. cinéma $\rightarrow$ ciné $\quad(\text { si'ne })_{\mathrm{Ft}}$ 'cinema' b. réfrigérateur $\rightarrow$ frigo $(\text { fri' } \mathrm{go})_{\mathrm{Ft}}$ 'refrigerator'

Another piece of evidence consistent with foot structure in French comes from patterns of stress clash resolution in compounds and DPs with attributive adjectives (5) (Mazzola 1992, 1993; Hoskins 1993; Post 
2000, 2003). For example, in compound names, the last (non-schwa) syllable of each constituent can be realized as prominent (5a). ${ }^{1}$ However, in cases where the second constituent is monosyllabic, stress on the first name must retract (or delete; see note 1), thus avoiding a clash (5b).

(5) a. [ma, rikris'tın] Marie-Christine b. [,mari'roz], *[ma, ri'roz $]$ Marie-Rose

The four types of data presented in this section reflect the uneven landscape for (Québec) French: prosodic patterns have been used as evidence to both motivate and contest the existence of foot structure in this language. As it is difficult to evaluate the (non-)existence of the foot based on prosodic patterns alone, it is necessary to investigate whether other types of phenomena, such as segmental processes, apply with reference to this domain. The type of case to consider is processes that involve the weakening or deletion of segments, as these are often conditioned by foot structure crosslinguistically, with the weakened or deleted segment being in the dependent position of the foot. In the next subsection, we will briefly examine two weakening processes in Québec French, namely, high vowel devoicing and high vowel deletion, as candidates for processes that are conditioned by foot structure.

2.1 Segmental phenomena and word-internal constituency in Québec French Two weakening processes target high vowels in Québec French, devoicing and deletion, both of which apply variably with high rates of occurrence (e.g., Walker 1984; Cedergren and Simoneau 1985; Bayles 2016); see (6).

(6) a. High Vowel Devoicing:

précipiter [presịpite] $\sim$ [presipịte] [presipiste] 'to hasten'

b. High Vowel Deletion:

précipiter [presØpite] [presipØte]

Devoicing and deletion have distinct segmental conditioning: while devoicing is conditioned by adjacent voiceless consonants (especially by preceding ones), deletion is insensitive to the voicing of adjacent segments (e.g., [kõbØne], but *[kõbine] combiner 'to combine') (Walker 1984; Cedergren 1986). Neither process targets word-final vowels, which may suggest that both are sensitive to rhythm in some way. However, the fact that devoicing can apply in adjacent syllables questions this (e.g., [presipite]). Deletion, in contrast, cannot target adjacent syllables (*[presØpØte]), even though long words can have multiple deleted vowels (e.g., [ynØversØte] université 'university'). In short, devoicing suggests an analysis involving overlapping gestures; deletion, on the other hand, appears to be rhythmically constrained. ${ }^{2}$

Since the voicing of adjacent segments cannot predict the occurrence of high vowel deletion in Québec French, an alternative approach is warranted. Indeed, as mentioned earlier, Verluyten (1982) has argued that deletion is sensitive to alternating rhythmic structure. Specifically, deletion preferably applies in evennumbered syllables from the right edge of the word, the syllables that Verluyten (1982) considers to be weak in French metrical structure, as shown in (7).

(7) Verluyten's (1982) analysis of high vowel deletion:

a. Preferred context:

$\begin{array}{llllll}\mathrm{s} & \mathrm{W} & \mathrm{s} & \mathrm{w} & \mathrm{s}\end{array}$

a $1 \varnothing$ mã ta sjõ alimentation 'nourishment'

\footnotetext{
${ }^{1}$ Two alternative pronunciations exist for compound names: (i) only the rightmost syllable is realized as prominent, e.g., [marikris'tın]; (ii) the left- and rightmost syllables are realized as prominent, consistent with the pattern observed in the first example in each of (3a) and (3b), e.g., [, marikris'tin].

${ }^{2}$ For more on these two processes in Québec and European varieties of French, see Gendron (1966); Dumas (1972, 1987); Walker (1984); Cedergren and Simoneau (1985); Ouellet et al. (1999); Torreira and Ernestus (2010); and Bayles (2016).
} 
b. Dispreferred context:

$\mathrm{S} \quad \mathrm{W} \quad \mathrm{S} \quad \mathrm{W} \quad \mathrm{s}$

or ga $\mathrm{n} \varnothing$ za tœr organisateur 'organizer'

However, we have already seen that Verluyten's (1982) position has been challenged by Cedergren (1986), who, in an analysis of sociolinguistic data, did not find any evidence to support the hypothesis that high vowel deletion is rhythmically conditioned. In Cedergren's (1986) account, thus, the two forms in (7) are considered to be equally possible in Québec French.

In order to experimentally probe whether high vowel deletion is conditioned by alternating rhythmic structure, which would motivate the existence of foot structure in Québec French, we investigated native speakers' preferences regarding the application of the process. The next section describes our experimental design and procedures.

\section{Methods}

We tested the rhythmic conditioning of high vowel deletion in Québec French through a perceptual judgement task. The stimuli included words containing 3 to 6 syllables $(n=275)$, with or without deletion of [i] in non-final position. We included only [i] because it is reported to be the high vowel that most frequently deletes in Québec French (Walker 1984). Furthermore, given that high vowel deletion is a variable process, it was not our intention to analyze whether vowel quality conditions the process, but instead, the rhythmic constraints that underlie it.

The target vowels never followed branching onsets or preceded codas, following Cedergren's (1986) observation that deletion does not apply in these contexts (cf. Verluyten 1982). The target words also did not contain schwa; as schwa is the most deletable vowel in Québec French, we did not want judgements about deletion or non-deletion of [i] to be confounded by the presence of schwa elsewhere in a word.

In the target words with deletion, the process applied in either foot-head or foot-dependent position. Words with deletion in foot-head position exhibited the process in syllables 3 or 5 from the right edge of the word (e.g., [or.ga.nØ.za.tœr] 'organizer', [ka.pØ.ta.li.za.sjõ] 'capitalization'), while words with deletion in foot-dependent position exhibited the process in syllables 2 or 4 (e.g., [kõ.bØ.ne] 'to combine', [ma.nØ.fes.ta.sjõ] 'demonstration').

In addition, the consonantal string resulting from deletion in target words either mirrored or failed to mirror a well-formed branching onset in French (e.g., [pr] as in [supØre] 'to sigh' $v s$. *[bn] as in [robØnc] 'faucet'; note that *[bn] also does not correspond to a well-formed coda-onset cluster in the language). Finally, we also included words in which deletion applied at a suffix boundary (e.g., [Eksklyziv-Øte] 'exclusivity'), to compare with words where it applied in the root (e.g., [imØtatœr] 'impersonator').

These three conditions on the generation of stimuli (position of deletion in the foot, resulting consonantal cluster, and morphology) were included in the analysis as variables. See Table 1 for examples of deletion sites for each variable.

Table 1: Variables included in the analysis.

\begin{tabular}{|c|c|c|}
\hline Position of deletion in foot & 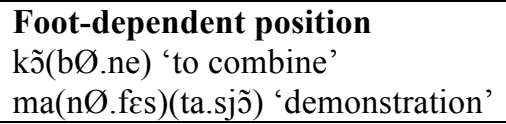 & $\begin{array}{l}\text { Foot-head position } \\
\text { or(ga.nØ)(za.tœr) 'organizer' } \\
(\text { ka.pØ)(ta.li)(za.sjõ) ‘capitalization' }\end{array}$ \\
\hline Resulting consonantal cluster & $\begin{array}{l}\text { Well-formed branching onset } \\
\text { [pr] supØre 'to sigh' } \\
\text { [bl] abØlite 'ability' }\end{array}$ & $\begin{array}{l}\text { Ill-formed branching onset } \\
* \text { [bn] robØn } \varepsilon \text { 'faucet' } \\
*[\mathrm{mt}] \text { imØtatœr 'impersonator' }\end{array}$ \\
\hline Morphology & $\begin{array}{l}\text { Deletion at suffix boundary } \\
\text { عksklyziv-Øte 'exclusivity' } \\
\text { inisjal-Øzasjõ 'initialization' }\end{array}$ & $\begin{array}{l}\text { Deletion within root } \\
\text { imØtatœr 'impersonator' } \\
\text { alØmãtasj̃̃ 'nourishment' }\end{array}$ \\
\hline
\end{tabular}

The stimuli also contained fillers $(n=144)$, which exhibited presence or absence of deletion of mid or low vowels. All the stimuli were recorded by a female native speaker of Québec French with training in linguistics. Deletion was produced naturally in the stimuli, and the presence or absence of [i] was later 
checked in Praat (Boersma and Weenink 2016).

The experiment was constructed in Praat, with the stimuli ordered pseudorandomly. Each item was presented to participants both orthographically and auditorily. Orthographic presentation was necessary to ensure that participants knew which lexical item they had to judge. ${ }^{3}$ Each item followed a beep and was played only once. Participants were instructed to judge whether the words that they heard were pronounced in a natural way using a 5-point scale that ranged from completely unnatural to completely natural. They made their judgements using the keys from 1 to 5 on the computer keyboard.

The participants were ten native speakers of Québec French, all raised in the Montréal area. They were tested in separate sessions in a sound-attenuated booth in the Department of Linguistics at McGill University. Each session lasted about 40 minutes including two five-minute breaks.

3.1 Predictions As mentioned above, our stimuli were controlled based on the variables presented in Table 1. Given these variables, our predictions are as follows:

(i) Overall, participants will judge the application of HVD to be natural, given that the process is reported to be frequently attested in Québec French (e.g., Walker 1984; Cedergren 1986).

(ii) Position of deletion in foot: If HVD is conditioned by alternating rhythmic structure, participants will prefer its application in even-numbered syllables from the right word edge. HVD in syllables 2 and 4 will be equally preferred, while it will be equally dispreferred in syllables 3 and 5 .

(iii) Resulting consonantal cluster: HVD will be preferred when the resulting cluster mirrors an illformed branching onset in Québec French. Words in which HVD results in a string that corresponds to an ill-formed onset cluster can map to only one input representation, whereas words in which HVD results in a string that corresponds to a well-formed onset cluster have indeterminate inputs. To exemplify, an item

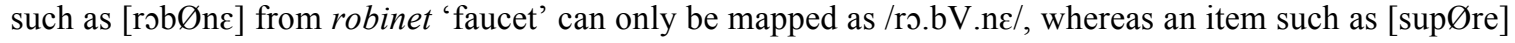
from supirer 'to sigh' can be mapped either as /su.pre/ or /su.pV.re/ (V stands for any deletable vowel).

(iv) Morphology: HVD will be preferred at a suffix boundary, because the deleted vowel is easily recovered in this context. This is because there is a disproportionate number of derivational suffixes in French that begin with [i].

\section{Results}

4.1 Data Before considering participants' preferences in light of the variables in Table 1, we examine their overall preference for deletion $v s$. non-deletion. In general, non-deletion is preferred over deletion (non-deletion: mean $=4.48, \mathrm{SD}=0.94$; deletion: mean $=3.28, \mathrm{SD}=1.50$ ). However, the mean for deletion is well above 2.5, which indicates that although deletion is less preferred than non-deletion, it is not rejected by participants. This appears to be consistent with prediction (i).

In Figure 2, we present participants' responses by position in foot. The similarity between responses in both conditions confirms that HVD is indeed frequent in the language. However, the figure also shows a higher concentration of 4-5 responses in cases where deletion occurs in foot-dependent position, which suggests that participants find it more natural relative to deletion in foot-head position. Speakers also seem to be less certain in cases where deletion occurs in foot-head position, as evidenced by the higher concentration of 3 responses in the second panel of Figure 2. The data in Figure 2 thus appears to be consistent with prediction (ii).

\footnotetext{
${ }^{3}$ If participants heard a word such as pilaire 'of the hair' with deletion of [i] (i.e., [pØler]) and no orthographic form was provided, they could be confused as to whether the target word was indeed pilaire or plaire 'to enjoy' ([pler]), which could impact their judgements. We avoided word pairs of this type in our experiment.
} 
Figure 2: Participants' responses by position in foot $(1=$ completely unnatural; $5=$ completely natural $)$.

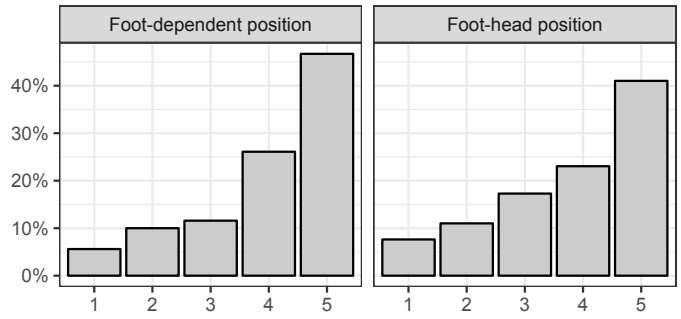

If we now examine Figure 3, we can see that resulting consonantal cluster also affects speakers' responses: deletion is clearly dispreferred if the resulting cluster yields a string mirroring a well-formed branching onset in French. In other words, deletion in supirer ([pr]) is considered less natural than deletion in robinet $(*[\mathrm{bn}])$. This suggests that prediction (iii) is supported.

Figure 3: Participants' responses by resulting consonantal cluster $(1=$ completely unnatural; $5=$ completely natural).

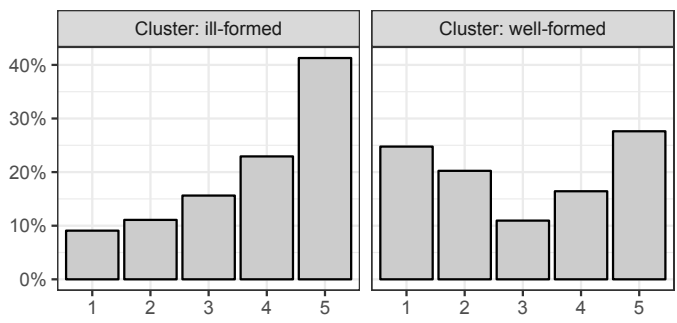

Finally, morphology also affects speakers' judgements. However, as it interacts with position in foot, we will reserve discussion of this variable until section 4.2 .

4.2 Statistical analysis Participants' judgements were modelled using a hierarchical ordinal regression with by-speaker and by-item random intercepts in R (R Core Team). The model controlled for participants' preferences regarding deletion vs. non-deletion, and included the variables in Table 1 as main effects. The model also included an interaction between position in foot and morphology. This section only reports on the results that were statistically significant in the model $(\mathrm{p}<0.05)$.

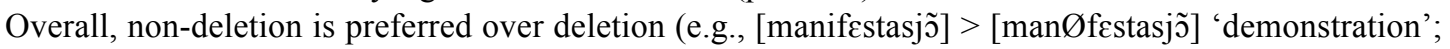
$\hat{\beta}=2.11, \mathrm{SE}=0.30, z=6.96)$.

The results for position of deletion in foot indicate that HVD is preferred in even-numbered syllables

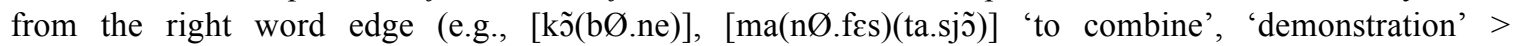
[or(ga.nØ)(za.tœr)], [(ka.pØ)(ta.li)(za.sjõ)] 'organizer', 'capitalization'; $\hat{\beta}=0.46, \mathrm{SE}=0.19, z=2.4)$. Furthermore, HVD in syllables 2 and 4 was equally preferred, and HVD in syllables 3 and 5 was equally dispreferred. Taken together, these findings support the view that Québec French builds iterative iambs from the right word edge, with deletion preferred in the dependent position of any foot in the word.

Regarding resulting consonantal cluster, HVD is preferred when it yields strings mirroring ill-formed branching onsets in French (e.g., [robØnc], [imØtatœr] 'faucet', 'impersonator' > [supØre], [abØlite] 'to sigh', 'ability'; $\hat{\beta}=1.05, \mathrm{SE}=0.27, z=3.9$ ). We propose that deletion is dispreferred when the resulting cluster could be parsed as a well-formed branching onset because it becomes more difficult to recover the underlying form. This suggests that the application of HVD does not lead to resyllabification. And if the syllabification remains intact, it follows that the foot structure remains intact.

Finally, with respect to morphology, the model indicated that deletion is preferred over non-deletion in one context: when [i] is at the left edge of a suffix and in foot-dependent position (e.g., [Eksklyziv-Øte] $>$ [cksklyziv-ite] 'exclusivity'; $\hat{\beta}=1.62, \mathrm{SE}=0.27, z=6$ ). 


\section{Formalization}

In this section, we formalize the results described above in a MaxEnt Grammar (Goldwater and Johnson 2003; Hayes and Wilson 2008). MaxEnt is a constraint-based probabilistic framework in which constraints are weighted and candidates are assigned scores (denoted by $h(x)$ in the tableaux below), which are in turn converted into probabilities. Scores are defined as the sum of all violations a candidate incurs multiplied by the respective weight of each violated constraint. A MaxEnt value is then calculated by negating each candidate's score, and raising $e$ (the base of the natural logarithm) to the result. Finally, the probability is calculated by dividing each MaxEnt value by the sum of all values in the candidate set. If constraint $\mathrm{A}$ has a higher weight relative to constraint $\mathrm{B}$, this entails that candidates that violate constraint A will be more severely penalized (i.e., will have a lower MaxEnt value), and will thus be less likely to occur (all other violations being equal in the grammar).

Because this framework assigns probabilities to candidates, non-categorical phenomena such as HVD can be captured straight-forwardly. Constraints that are violated by candidates that are more frequently observed in the language are necessarily assigned lower weights in the grammar. The acquisition task in a MaxEnt grammar thus involves acquiring a set of constraint weights such that the probabilities of candidates which are more frequently found in the language are maximized in relation to those of less frequent candidates.

Learning the constraint weights in question can be simulated using the MaxEnt grammar tool developed in Wilson (2006) (see also Hayes and Wilson 2008). However, in the analysis that follows, we have instead employed weights that impressionistically mirror the statistical results discussed in section 4.2. The objective is to show the relative weights that are necessary to generate the patterns observed in the data. Importantly, given that our statistical model takes into account by-speaker and by-item variation through random intercepts, this is a more conservative approach than the typical MaxEnt implementation.

The first pattern that needs to be accounted for is the overall preference for non-deletion over deletion. This is achieved by the interaction of two constraints, namely, MAX and $* \mathrm{i}$, defined in (8).

(8) MAX: Do not delete

*i: Low sonority vowels are disfavoured

Since deletion is dispreferred, the weight of MAX needs to be greater than the weight of $* i$. In the tableau in (9), the form in (a) is more likely to occur $(p(a)=0.55)$ than the form in (b) $(p(b)=0.45)$.

\begin{tabular}{|c|c|c|c|c|}
\hline & $W=1.7$ & $W=1.5$ & & \\
\hline /manifestasjã / & MAX & $*_{\mathrm{i}}$ & $h(x)$ & $p(x)$ \\
\hline a. [manifধstasjĩ] & & 1 & 1.5 & 0.55 \\
\hline b. [manØfestasjõ] & 1 & & 1.7 & 0.45 \\
\hline
\end{tabular}

The statistical analysis revealed that HVD is preferred in foot-dependent positions within the word. To account for this preference, we employ the positional faithfulness constraint MAX-HD, defined in (10).

(10) MAX-HD: Do not delete in foot-head position

Given that the combined weight of MAX-HD and MAX is necessarily greater than the weight of $* \mathrm{i}(w=1.5)$, we capture the finding that the preference for non-deletion is even stronger when it occurs in foot-head position. In other words, the relative weight of these constraints ensures that, between the two candidates with HVD in the tableau in (11), the one with deletion in foot-dependent position is preferred $(b>b$ ';

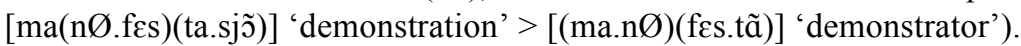




\begin{tabular}{|c|c|c|c|c|c|}
\hline & $W=1.7$ & $W=1.5$ & $W=0.4$ & & \\
\hline 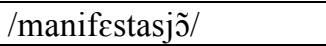 & MAX & $*_{\mathrm{i}}$ & MAX-HD & $h(x)$ & $p(x)$ \\
\hline a. $[\mathrm{ma}($ ni.f $\varepsilon s)(\mathrm{ta} . \mathrm{sj} \tilde{)})]$ & & 1 & & 1.5 & 0.55 \\
\hline \multirow{2}{*}{ b. $[\mathrm{ma}(\mathrm{n} \emptyset . \mathrm{f} \varepsilon \mathrm{s})($ ta.sjõ $)]$} & 1 & & & 1.7 & 0.45 \\
\hline & $W=1.7$ & $W=1.5$ & $W=0.4$ & & \\
\hline /manifestã/ & MAX & $*_{\mathrm{i}}$ & MAX-HD & $h(x)$ & $p(x)$ \\
\hline $\mathrm{a}^{\prime} .[(\mathrm{ma} \cdot n i)(\mathrm{f} \varepsilon s . t \tilde{a})]$ & & 1 & & 1.5 & 0.65 \\
\hline $\mathrm{b}^{\prime} .[(\mathrm{ma} . \mathrm{n} \emptyset)(\mathrm{f} \varepsilon \mathrm{s} . \mathrm{ta})]$ & 1 & & 1 & 2.1 & 0.35 \\
\hline
\end{tabular}

The statistical analysis indicated a preference for HVD resulting in strings that mirror ill-formed branching onsets in Québec French. We propose that the constraint RECOVERABILITY expresses this preference. This constraint is defined in (12).

(12) RECOVERABILITY: In a segmental string, immediate precedence relations in the input are recoverable in the perceived output

As discussed earlier, a form produced as [robne] can be recovered by the listener only as /ro.bV.ne/. Given that the sequence [bn] is not a possible branching onset in Québec French, listeners cannot recover it as /ro.bne/, where the two members of the cluster are string-adjacent. (They can also not recover it as /rob.ne/, as [bn] is not a well-formed coda-onset cluster in the language.) Productions such as [supre], where HVD yields a string that mirrors a licit branching onset, on the other hand, can be mapped by the listener to two possible inputs, with or without a vowel between the two members of the cluster (/su.pV.re/ or /su.pre/). RECOVERABILITY is not respected here, as the presence or absence of deletion is indeterministic. More generally, then, RECOVERABILITY is violated when a unique input cannot be posited for a given production (perceived output). The tableau in (13) illustrates the role of RECOVERABILITY. Given the constraint violations exhibited by the candidates with HVD, the preferred candidate is the one where HVD yields a string that mirrors an ill-formed branching onset (b > b'; [ro(bØ.nc)] 'faucet' > [su(pØ.re)] 'to sigh').

\begin{tabular}{|l|c|c|c|c|c|}
\hline & $W=1.7$ & $W=1.5$ & $W=1.1$ & & \\
\hline /robinc/ & MAX & $*_{\mathrm{i}}$ & RECOVER & $h(x)$ & $p(x)$ \\
\hline a. [ro(bi.nc)] & & 1 & & 1.5 & 0.55 \\
\hline b. [ro(bØ.nc)] & 1 & & & 1.7 & 0.45 \\
\hline & $W=1.7$ & $W=1.5$ & $W=1.1$ & & \\
\hline /supire/ & MAX & $*_{\mathrm{i}}$ & RECOVER & $h(x)$ & $p(x)$ \\
\hline a'. [su(pi.re)] & & 1 & & 1.5 & 0.79 \\
\hline b'. [su(pØ.re)] & 1 & & 1 & 2.8 & 0.21 \\
\hline
\end{tabular}

Finally, the statistical analysis showed that morphology interacts with position of deletion in foot: speakers reverse their overall preference for non-deletion in words where HVD applies at a suffix boundary, in footdependent position. The constraint that accounts for HVD at a suffix boundary is ${ }_{\text {Af }}[\mathrm{i}$, which is defined in (14):

(14) * ${ }_{\text {Af }}[\mathrm{i}$ : Low sonority vowels are disfavoured at affix boundaries

The interaction between $*_{\mathrm{i}}$ and $*_{\text {Af }}[\mathrm{i}$ generates a gang-up effect: the weight of these two constraints combined is greater than the weight of MAX. The tableau in (15) illustrates the gang-up effect. 
(15)

\begin{tabular}{|l|c|c|c|c|c|c|}
\hline & $w=1.7$ & $w=1.5$ & $w=0.6$ & $w=0.4$ & & \\
\hline /عksklyziv-ite/ & MAX & $*_{\mathrm{i}}$ & ${ }^{*}{ }_{\text {Af }}[\mathrm{i}$ & MAX-HD & $h(x)$ & $p(x)$ \\
\hline a. $[$ Eks(kly.zi)(v-i.te)] & & 2 & 1 & & 3.6 & 0.4 \\
\hline b. $[$ cks(kly.zi)(v-Ø.te)] & 1 & 1 & & & 3.2 & 0.6 \\
\hline
\end{tabular}

However, the gang-up effect is mitigated by MAX-HD: if [i] is at a suffix boundary and in foot-head position, deletion and non-deletion are equally preferred, as shown in the tableau in (16).

\begin{tabular}{|c|c|c|c|c|c|c|}
\hline & $w=1.7$ & $w=1.5$ & $w=0.6$ & $w=0.4$ & & \\
\hline /inisjal-izasjã/ & MAX & $*_{\mathrm{i}}$ & $*_{\mathrm{Af}}[\mathrm{i}$ & MAX-HD & $h(x)$ & $p(x)$ \\
\hline a. [(i.ni)(sja.l-i)(za.sjõ)] & & 3 & 1 & & 5.1 & 0.5 \\
\hline b. [(i.ni)(sja.1-Ø)(za.sjõ)] & 1 & 2 & & 1 & 5.1 & 0.5 \\
\hline
\end{tabular}

In sum, the constraints and (relative) weights proposed capture the patterns of HVD based on speakers' ratings. They also appropriately formalize the gang-up effect observed.

\section{Conclusion}

In this paper, we tested the hypothesis that high vowel deletion (HVD) is conditioned by foot structure in Québec French. The statistical model indicated that HVD is preferred in even-numbered syllables from the right word edge. This is consistent with the proposal that Québec French builds iterative iambic feet, despite the fact that the language lacks the typical signatures for stress and footing as well as the inconclusive evidence for footing from other types of prosodic phenomena. The results show that even though Verluyten (1982) and Cedergren (1986) disagree on the rhythmic conditioning of HVD, they are both correct: HVD can apply in any position upstream of the final vowel (Cedergren), but is preferred in foot-dependent positions (Verluyten).

The results for resulting consonantal cluster suggest that HVD does not alter syllabification and, thus, not footing: native speakers prefer HVD when the resulting consonantal cluster mirrors an ill-formed branching onset in French, that is, in items that can be uniquely mapped to inputs containing a vowel between the consonants in the cluster.

Finally, our probabilistic approach formalized the rhythmic constraints that underlie speakers' preferences regarding the application of HVD.

\section{References}

Bayles, Andrew John. (2016). High vowel lenition in the French of Quebec and Paris. MA thesis, University of Utah. Boersma, Paul and Weenink, David. (2016). Praat: Doing phonetics by computer [Computer program]. Version 6.0.23.

Cedergren, Henrietta J. (1986). Metrical structure and vowel deletion in Montreal French. In Sankoff, David (ed.) Diversity and diachrony, pp. 293-300. Philadelphia: Benjamins.

Cedergren, Henrietta J. and Simoneau, Louise. (1985). La chute des voyelles hautes en français de Montréal: As-tu entendu la belle syncope? In Lemieux, Monique and Cedergren, Henrietta J. (eds.) Les tendances dynamiques du français parlé à Montréal, pp. 57-145. Vol. 1. Québec: Office de la langue française.

Déchaine, Rose-Marie. (1990). Stress and weight gain. Ms., University of Massachusetts, Amherst.

Dell, François. (1984). L'accentuation dans les phrases en français. In Dell, François, Hirst, Daniel and Vergnaud, Jean-Roger (eds.) Forme sonore du langage, pp. 65-122. Paris: Hermann.

Dumas, Denis. (1972). Le français populaire de Montréal: Description phonologique. PhD dissertation, Université de Montréal.

Dumas, Denis. (1987). Nos façons de parler: Les prononciations en français québécois. Québec: Presses de l’Université du Québec.

Fónagy, Ivan. (1979). L'accent français: Accent probabilitaire. In L'accent en français contemporain, pp. $123-233$. Montréal: Didier.

Gendron, Jean-Denis. (1966). Tendances phonétiques du français parlé au Canada. Laval, QC: Presses de l'Université 
Laval.

Goad, Heather and Prévost, Adèle-Elise. (2011). A test case for markedness: The acquisition of Québec French stress. Ms., McGill University.

Goldwater, Sharon and Johnson, Mark. (2003). Learning OT constraint rankings using a Maximum Entropy model. In Proceedings of the Stockholm workshop on variation within Optimality Theory, pp. 111-120.

Hayes, Bruce and Wilson, Colin. (2008). A maximum entropy model of phonotactics and phonotactic learning. Linguistic Inquiry 39(3): 379-440.

Hoskins, Steven. (1994). Secondary stress and clash resolution in French: An empirical investigation. In Issues and theory in Romance linguistics, pp. 35-47. Washington, DC: Georgetown University Press.

Jun, Sun-Ah and Fougeron, Cécile. (2000). A phonological model of French intonation. In Botinis, Antonis. (ed.) Intonation: Analysis, modelling and technology, pp. 209-242. Dordrecht: Kluwer.

Mazzola, Michael L. (1993). French rhythm and French segments. In Linguistic perspectives on the Romance languages, pp. 113-126. Amsterdam: Benjamins.

McCarthy, John and Prince, Alan. (1995). Generalized alignment. In Booij, Geert and van Merle, Jaap. (eds.) Yearbook of Morphology, pp. 79-153.

Nespor, Marina and Vogel, Irene. (1986). Prosodic phonology. Dordrecht: Foris.

Ouellet, Marise, Tzoukermann, Évelyne and Ménard, Lucie. (1999). High vowels /i, y, u/ in Canadian and Continental French: an analysis for a TTS system, Eurospeech 1999, Budapest (Hongrie), pp. 2331-2334.

Post, Brechtje. (2003). French phrasing and accentuation in different speaking styles. Oxford University Working Papers in Linguistics, Philology and Phonetics 8: 69-83.

R Core Team. (2016). R: A language and environment for statistical computing. R Foundation for Statistical Computing, Vienna, Austria. [Computer program].

Scullen, Mary Ellen. (1997). French prosodic morphology: A unified account. Bloomington: IULC.

Selkirk, Elisabeth O. (1984). Phonology and syntax: The relation between sound and structure. Cambridge, MA: MIT Press.

Selkirk, Elisabeth O. (1996). The prosodic structure of function words. In Morgan, James L. and Demuth, Katherine (eds.) Signal to syntax: Bootstrapping from speech to grammar in early acquisition, pp. 187-213. Mahwah, NJ: Lawrence Erlbaum.

Thibault, Linda and Ouellet, Marise. (1996). Tonal distinctions between emphatic stress and pretonic lengthening in Quebec French. Proceedings of the International Spoken Language Conference 1996, Philadelphia, pp. 638-641.

Torreira, Francisco and Ernestus, Mirjam. (2010). Phrase-medial vowel devoicing in spontaneous French. Insterspeech 2010, pp. 2006-2009.

Verluyten, Sylvain Paul Marcel. (1982). Recherches sur la prosodie et la métrique du français. PhD dissertation, Universiteit Antwerpen.

Vogel, Irene. (2010). Universals of prosodic structure. In. Scalise, Sergio, Magni, Elisabetta and Bisetto, Antonietta (eds.) Universals of language today, pp. 59-82. Dordrecht: Springer.

Walker, Douglas C. (1984). The pronunciation of Canadian French. Ottawa: University of Ottawa Press.

Wilson, Colin. (2006). Learning phonology with substantive bias: An experimental and computational study of velar palatalization. Cognitive Science 30(5): 945-982. 